\title{
C-myb Antisense Oligonucleotide G4460
}

National Cancer Institute

\section{Source}

National Cancer Institute. C-myb Antisense Oligonucleotide G4460. NCI Thesaurus. Code C1541.

A 24-base phosphorothiolate antisense oligodeoxynucleotide (ODN) for the protooncogene c-myb with potential antineoplastic activity. C-myb antisense oligonucleotide G4460 binds to codon sequences 2 to 9 of c-myb mRNA, inhibiting translation of the transcript. Suppression of c-myb expression with this agent may result in the restoration of normal differentiation pathways, increased antiproliferative effects, and the induction of apoptosis in early progenitor hematopoietic cells and in tumor cells that overexpress c-myb. Tumor-cell overexpression of c-myb blocks differentiation, promotes proliferation, and inhibits apoptosis. 